\title{
Energy Consumption Analysis of Ad hoc Routing Protocols for Different Energy Models in MANET
}

\author{
Rohit Sangwan ${ }^{1}$, Dr. Manoj Duhan ${ }^{2}$, Sachin Dahiya ${ }^{3}$ \\ ${ }^{1,2}$ DCR University of Science \& Technology, Murthal, Sonipat(HR), India \\ ${ }^{3}$ Ch. Devi Lal Memorial Govt. Engineering College, Sirsa(HR), India
}

\begin{abstract}
In Mobile Ad hoc Networks (MANETs), energy conservation is a critical issue as the nodes are powered by the batteries which have limited energy reservoir. Hence the power level of the nodes is a problematical factor that extensively affects the performance and efficiency of ad hoc routing protocols. The rapidly changing traffic pattern the mobility of the nodes and the lack of fixed infrastructure makes routing in a MANET a challenging issue. So one of the main issues in MANET routing protocols is the development of energy efficient and QoS aware routing protocols which requires the energy analysis of routing protocols so that some modifications can be suggested. This paper presents performance comparison of three categories of mobile ad hoc routing protocols i.e. proactive, reactive and hybrid. The performance analysis is based on different metrics of Physical Layer such as Power Consumed in Transmit Mode, Power Consumed in Receive and Idle Modes, and metrics of application layer like Average End to End Delay, Average Jitter, Throughput and Packet Delivery Ratio based on the simulation analysis. Simulation analysis is performed over well known network simulator QualNet 6.1.
\end{abstract}

Keywords - MANET, AODV, DYMO, OLSR, PDR.

\section{INTRODUCTION}

A mobile ad hoc network (MANET) [1] is a collection of mobile nodes which dynamically form a temporary network to communicate without using any existing infrastructure, access point or central administration. The nodes moves randomly and organize themselves to form an arbitrary topology. Without a fixed infrastructure, ad hoc networks have to rely on portable, limited power sources. The issue of energy efficiency [2] is one of the most important problems in ad hoc networks. The energy can be consumed either during processing or communication. The energy consumed during communication is more dominant than the energy consumed while processing. Thereby, the communication system must be energy efficient by optimizing the energy consumption at different states of the communication. Since the batteries has limited energy reservoir, so a general constraint of wireless ad hoc communication is the short lifetime of mobile terminals. Although the battery technology is improving over time, but the need for energy consumption will not reduce. So as far as energy consumption concerned, we should try to save power while maintaining high connectivity. Hence overall performance becomes highly dependent on the energy efficiency of the algorithm because it directly relates to the operational lifetime of the network. Therefore, power management is one of the most challenging issues in mobile ad hoc networks.

This paper addresses the performance comparison of different categories of routing protocols [3] i.e. proactive protocols like OLSR and FSR, reactive protocols like AODV, DSR, DYMO and hybrid protocols like ZRP, based on different metrics of Physical Layer such as Energy Consumed in Transmit mode, Energy Consumed in Receive mode, Energy Consumed in Idle Mode metrics of application layer like Average End to End Delay, Average Jitter, Throughput and Packet Delivery Ratio based on the simulation analysis on simulation tool QualNet 6.1.The paper is organized as follows. Sections 2 briefly describes the classification of Ad hoc Routing Protocols. Section 3 discusses the different energy consumption modes and radio energy models. Section 4 gives the details of simulation setup and simulator QualNet 6.1. The simulation results are shown in section 5 and finally sections 6 conclusions are drawn.

\section{Ad Hoc Routing Protocols}

A routing protocol governs the way through which two communication entities exchange information; it includes the procedure of establishing a route, decision in forwarding information and action in maintaining the route and/or recovering from the routing failure. In MANETs, the routing protocols can be divided into three categories [1], [3] :

\subsection{Proactive Routing Protocols}

Proactive protocols are also called as Table-driven routing protocols in which the nodes keep the up-todate routes to all the destinations in the network by exchanging topological information. Each node maintains 
routing tables to store such information. These tables are updated periodically in order to maintain latest view of the network. The advantage of proactive protocols is that there is a minimal time delay for applications. However, it requires additional messaging overhead in order to maintain a consistent and up-to-date routing table, which consumes bandwidth and power and decreases throughput. The various Proactive protocols are: Fisheye State Routing protocol (FSR)[4],[5] Optimized Link State Routing protocol (OLSR)[8].

\subsection{Reactive Routing Protocols}

Reactive Routing Protocols, known as On-demand routing protocols are based on some kind of queryreply dialog approach. They do not maintain or constantly update their routing tables with the latest route topology. Whenever a source node has a packet to send to a destination node, then it initiates a route discovery to find the path to the destination node. After a route has been established, the route maintenance procedure is initiated to maintain this route. Since these protocols do not need periodic transmission of topological information of the network, so overhead messaging is reduced. The drawback of reactive protocols include high latency time in route finding and excessive flooding may lead to network clogging. e.g. Ad-hoc On Demand Distance Vector (AODV)[7], Dynamic Source Routing (DSR)[8], Dynamic Manet On Demand (DYMO)[9].

\subsection{Hybrid Routing Protocols}

The hybrid routing protocols for MANETs exploit hierarchical network architectures i.e. hybrid routing protocols are zone based, in which the network is partitioned or seen as a number of zones by each node where proactive maintains route within a zone and reactive maintains route in between zones through reactive flooding. The drawback of hybrid protocols is that success depends on amount of nodes participating and reaction to traffic depends on gradient of traffic volume. Example of hybrid protocol [12] is : Zone Routing Protocol (ZRP)[1],[3].

\section{RADIO ENERGY MODELS}

The Radio Energy Models [10] reads the energy consumption specifications of the radio where the specifications are defined by the configuration parameters which are the power supply voltage of the radio, electrical current load consumed in Transmit, Receive, Idle, and Sleep modes. Each state represents a different level of energy consumption.

- Transmit : node is transmitting a frame with transmission power $\mathrm{P}_{\mathrm{tx}}$;

- Receive : node is receiving a frame with reception power $P_{\mathrm{Ix}}$. That energy is consumed even if the frame is discarded by the node because it was intended for another destination, or it was not correctly decoded ;

- Idle (listening) : Even when no messages are being transmitted over the medium, the nodes stay idle and keep listening the medium with $\mathrm{P}_{\text {idle }}$;

- Sleep: when the radio is turned off and the node is not capable of detecting signals. No communication is possible. The node uses $\mathrm{P}_{\text {sleep }}$ that is largely smaller than any other power.

The energy dissipated in transmitting $\left(\mathrm{E}_{\mathrm{tx}}\right)$ or receiving $\left(\mathrm{E}_{\mathrm{rx}}\right)$ one packet can be calculated as:

$$
\begin{aligned}
& \mathrm{E}_{\mathrm{tx}}=\mathrm{P}_{\mathrm{tx}} \times \text { Duration } \\
& \mathrm{E}_{\mathrm{rx}}=\mathrm{P}_{\mathrm{rx}} \times \text { Duration }
\end{aligned}
$$

where 'Duration' denote the transmission duration of the packet.

\subsection{Micaz Radio Energy Model}

The MicaZ radio energy model is a radio-specific energy model which is pre-configured with the specification of power consumption of MicaZ motes (embedded sensor nodes).

Table 1. Specifications of MicaZ Energy Model

\begin{tabular}{|l|l|l|l|}
\hline Symbol & $\begin{array}{l}\text { MCU } \\
\text { Mode }\end{array}$ & Radio Mode & Radio @ 3V \\
\hline \multirow{4}{*}{$\mathrm{P}_{\mathrm{TX}}$} & Active & TX $(0 \mathrm{dBm})$ & $48.0 \mathrm{~mW}$ \\
\cline { 2 - 4 } & Active & TX $(-1 \mathrm{dBm})$ & $45.0 \mathrm{~mW}$ \\
\cline { 2 - 4 } & Active & $\mathrm{TX}(-3 \mathrm{dBm})$ & $42.0 \mathrm{~mW}$ \\
\cline { 2 - 4 } & Active & $\mathrm{TX}(-5 \mathrm{dBm})$ & $39.0 \mathrm{~mW}$ \\
\cline { 2 - 4 } & Active & $\mathrm{TX}(-7 \mathrm{dBm})$ & $36.0 \mathrm{~mW}$ \\
\cline { 2 - 4 } & Active & $\mathrm{TX}(-10 \mathrm{dBm})$ & $33.0 \mathrm{~mW}$ \\
\cline { 2 - 4 } & Active & $\mathrm{TX}(-15 \mathrm{dBm})$ & $26.4 \mathrm{~mW}$ \\
\hline $\mathrm{P}_{\mathrm{RX}}$ & Active & RX & $56.5 \mathrm{~mW}$ \\
\hline PCCA & Active & CCA & $55.8 \mathrm{~mW}$ \\
\hline P1 & Active & Idle & $10.79 \mathrm{~mW}$ \\
\hline
\end{tabular}




\begin{tabular}{|l|l|l|l|}
\hline PMCU & Active & Sleep & $1.50 \mathrm{~mW}$ \\
\hline PS & Sleep & Sleep & $30 \mu \mathrm{W}$ \\
\hline
\end{tabular}

\subsection{Mica Motes Radio Energy Model}

The Mica Motes radio energy model is a radio-specific energy model which is pre-configured with the specification of power consumption of Mica motes (embedded sensor nodes).

Table 2. Specifications of Mica Motes Energy Model

\begin{tabular}{|l|l|}
\hline Component & $\begin{array}{l}\text { Current } \\
(\mathbf{m A})\end{array}$ \\
\hline Radio & \multirow{2}{*}{9.60} \\
\hline RX & 9.0 \\
\hline $\begin{array}{l}\text { TX }(\mathrm{dBm}) \\
-20 \\
-5\end{array}$ & \\
0 & 5.30 \\
\cline { 2 - 2 } $\begin{array}{l}+5 \\
+20\end{array}$ & 8.90 \\
\cline { 2 - 2 } & 10.40 \\
\cline { 2 - 2 } & 14.8 \\
\cline { 2 - 2 } & 26.70 \\
\hline
\end{tabular}

\subsection{GENERIC RADIO ENERGY MODEL}

The main feature of the generic model is estimation of energy consumption for the radios with common modulation schemes (analog and digital) and common classes of amplifiers (class-A,B,C,D). Further, the model can estimate energy consumption in transmitter for the case of continuous transmit power level. The parameters which are optionally required for generic model to be able to more accurately estimate the power or the amount of current loaded on battery are:

- Amplifier drain efficiency $(\mu)$ : about $35 \%$ for class-A and about $75 \%$ for higher classes. The default value is $75 \%$.

- Peak to average power ratio $(\beta)$ : about 1 for digital modulation and $>1$ for QAM. The default value is 1 .

- The power supply voltage $\left(\mathrm{V}_{\mathrm{dd}}\right)$ : The default value is $3 \mathrm{~V}$.

- Idle power consumption $\left(\mathrm{P}_{\text {Idle }}\right)$ : If not configured, we consider reception power $\mathrm{P}_{\text {cr }}$ as the idle power consumption.

- Sleep power consumption $\left(\mathrm{P}_{\mathrm{sp}}\right)$ : The default value is $0 \mathrm{~mW}$.

Those parameters are all well-know parameters in RF circuit design; if the user configures them generic energy model is fairly accurate and works well in case of continuous and variable transmission power.

\subsection{QUaLnet 6.1}

\section{SIMULATION SET UP}

QualNet [11] is a comprehensive suite of tools for modeling large wireless and wired networks. It uses simulation and emulation process to predict the behavior and performance of networks to improve their design, operation \& management. It enables users to design new protocols, optimize new and existing protocols, designing of large wired and wireless networks using preconfigured or user-designed models, analyzing the performance of networks and perform what-if analysis to optimize the results. QualNet is a commercial product that grew out of GloMoSim simulator and it is distributed by Scalable Network Technologies. QualNet simulator is $\mathrm{C}++$ language based tool. All the protocols are implemented in a series of $\mathrm{C}++$ files and are called by the simulation kernel. QualNet simulator comes with java based graphical user interface (GUI). The QualNet Simulator has a scalable network library and provides accurate and efficient execution.

\subsection{Designing Of Scenario}

We have chosen QualNet version 6.1 over Windows platform for our simulation studies. QualNet is a discrete event simulator. It is equally capable of simulating various wired or wireless scenarios from simple to complex conditions. In our simulation model, there are 100 nodes and all of these are connected to one wireless station. The terrain condition we have set as $1500 \mathrm{~m} \times 1500 \mathrm{~m}$ as flat area. The entire area is further divided into 100 square shaped cells as shown in figure 1 . The type of wireless propagation model is Two Ray ground propagation. The entire connection set up has been done randomly. The battery model considered in our simulation is Panasonic AAA. The simulation is performed with CBR (Constant bit rate) traffic flow. The numbers of constant bit rate (CBR) connections are 9 as indicated in table 3 . 


\subsection{Simulation Scenario Snapshot}

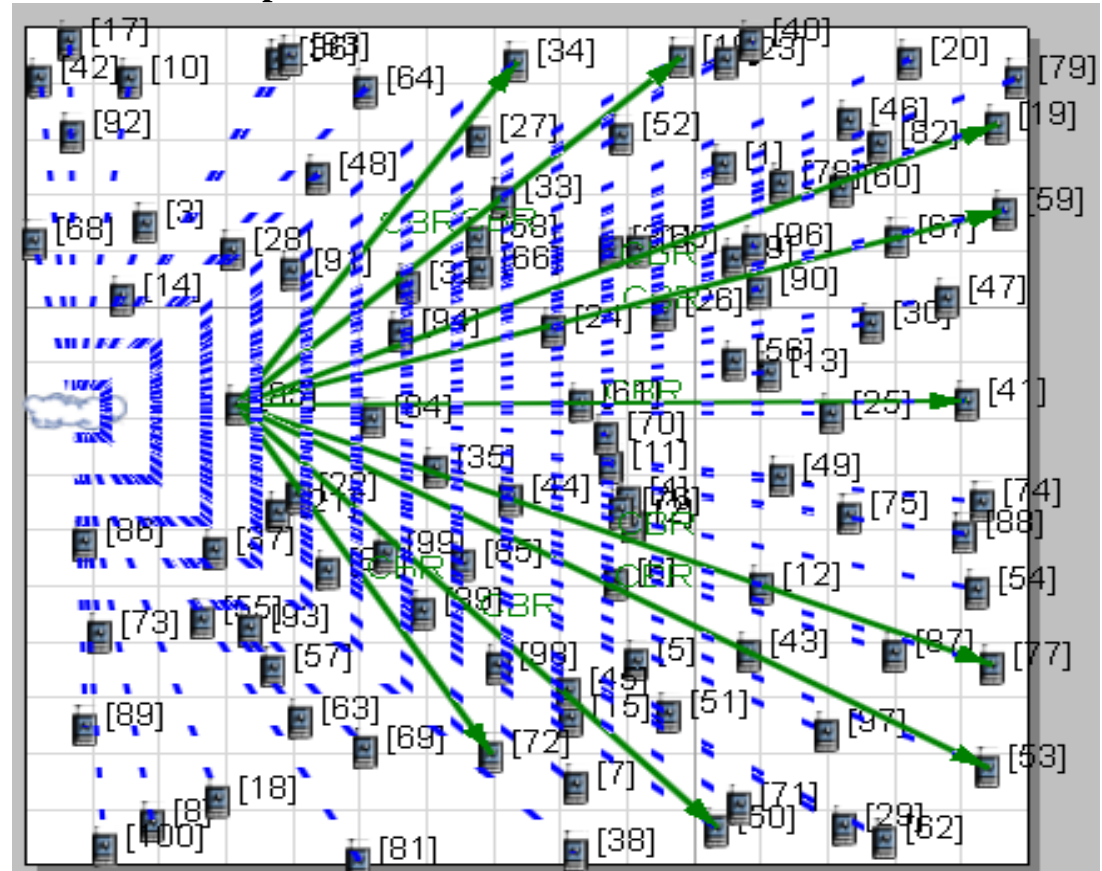

Figure 1. Snapshot of simulation scenario applying CBR between various nodes

Table 3. Parameters considered for simulation

\begin{tabular}{|c|c|c|}
\hline S.No. & Parameter & Value \\
\hline 1. & Simulator & QualNet Version 6.1 \\
\hline 2. & Terrain Size & $1500 \times 1500 \mathrm{~m}^{2}$ \\
\hline 3. & Antenna model & Omnidirectional \\
\hline 4. & No of nodes & 100 \\
\hline 5. & Radio Type & $802.11 \mathrm{~b}$ \\
\hline 6. & Data size & 512 bytes \\
\hline 7. & Data Rate & $2 \mathrm{Mbps}$ \\
\hline 8. & Mobility Model & Random Way Point \\
\hline 9. & Propagation Model & Two Ray Ground \\
\hline 10. & Channel Frequency & $2.4 \mathrm{GHz}$ \\
\hline 11. & Traffic Source & CBR \\
\hline 12. & Nodes Speed & Min. $=1 \mathrm{~m} / \mathrm{s}, \operatorname{Max} .=10 \mathrm{~m} / \mathrm{s}$ \\
\hline 13. & Position Granularity & 1.0 \\
\hline 14. & Pause Time & $30 \mathrm{~s}$ \\
\hline 15. & Battery Model Type & Residual life Estimator \\
\hline 16. & Routing Protocols & $\begin{array}{l}\text { Proactive : AODV, DSR, DYMO } \\
\text { Reactive : FISHEYE, OLSR } \\
\text { Hybrid : ZRP }\end{array}$ \\
\hline 17. & Battery Model & Panasonic AAA \\
\hline 18. & $\begin{array}{l}\text { Performance Metrics } \\
\text { in Application Layer }\end{array}$ & $\begin{array}{l}\text { PDR, Average Jitter, Average End } \\
\text { to End Delay, Throughput }\end{array}$ \\
\hline 19. & $\begin{array}{l}\text { Performance Metrics } \\
\text { in Physical Layer }\end{array}$ & $\begin{array}{l}\text { Energy consumed (in mjoules) in } \\
\text { Transmit mode } \\
\text { Energy consumed (in mjoules) in } \\
\text { Received mode } \\
\text { Energy Consumed (in mjoules) in } \\
\text { Idle mode }\end{array}$ \\
\hline
\end{tabular}

\section{Simulation RESULTS}

There are several different metrics [2], [12] that can be applied to measure the ad hoc routing protocols performance. The following metrics are used for the performance evaluations of different ad hoc routing protocols for mobile ad hoc networks :

\section{1) Energy Consumed in Transmit Mode :}

The fig. 2 shows that the energy consumed by FSR and OLSR protocols is highest which are proactive in nature and for AODV and DYMO is lowest which are reactive in nature and ZRP protocol consumes medium 
energy which is a hybrid protocol. The same behavior is observed for all the three radio energy models i.e Generic, MicaZ and Mica Motes. Further we can conclude that the energy consumption is highest for thee proactive protocols, lowest for reactive protocols and medium for hybrid protocols. By comparing the performance of protocols for each radio energy model we can deduce that the power consumption is highest for Generic model and lowest for the Mica Motes. So Mica Motes energy model seems to be more energy saving and the Generic model the least.

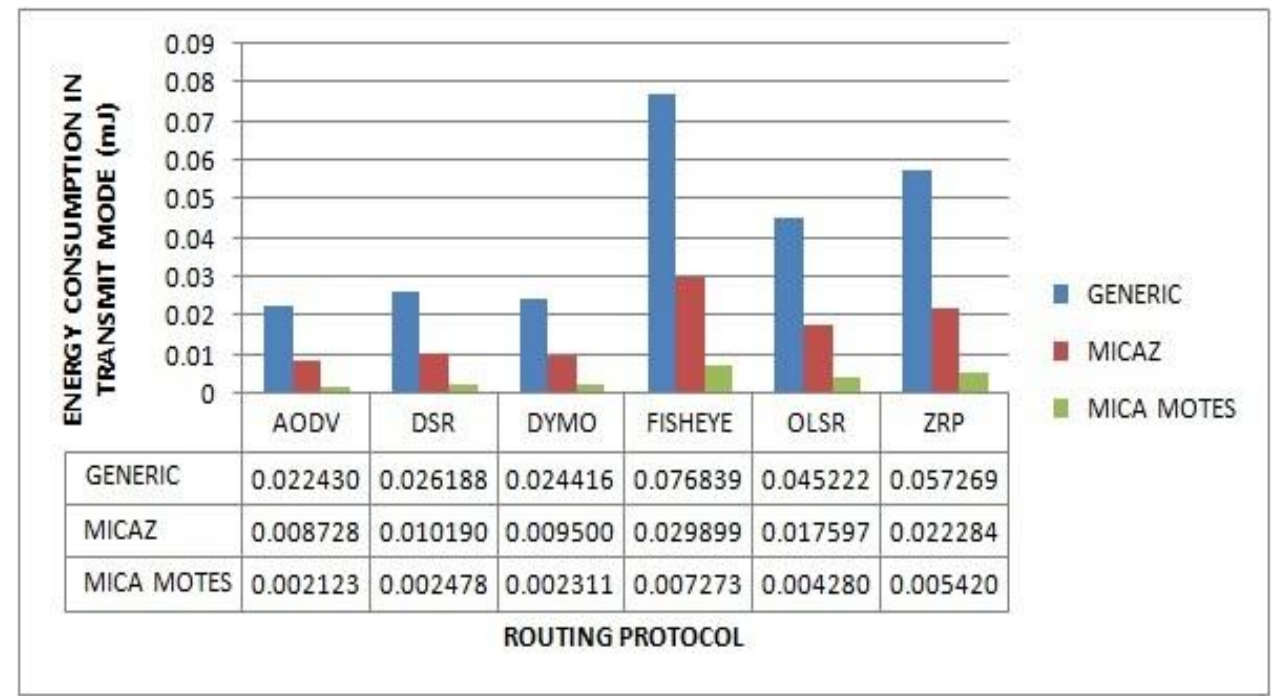

Fig. 2. Energy Consumed in Transmit Mode in Physical Layer for different Ad hoc Routing Protocols

\section{2) Energy Consumed in Transmit Mode :}

The fig. 3 shows similar type of results for energy consumed in Receive mode as obtained for the energy consumed in Transmit mode, but the energy consumed in the Receive mode is comparatively higher than energy consumed in Transmit mode. The proactive protocols like OLSR and FSR are having more energy consumption in Receive mode as compared to reactive protocols. The similar behavior is observed for all the three radio energy models i.e Generic, MicaZ and Mica Motes for each protocol with a single exception in case of ZRP protocol for the Generic model i.e for generic model the ZRP is having more energy consumption in Receive mode as compared to OLSR. Further the comparative results shows that the energy consumption is highest in case of Generic model and lowest in case of Mica Motes energy model. So the Generic model seems to be least energy saving and Mica Motes model the most.

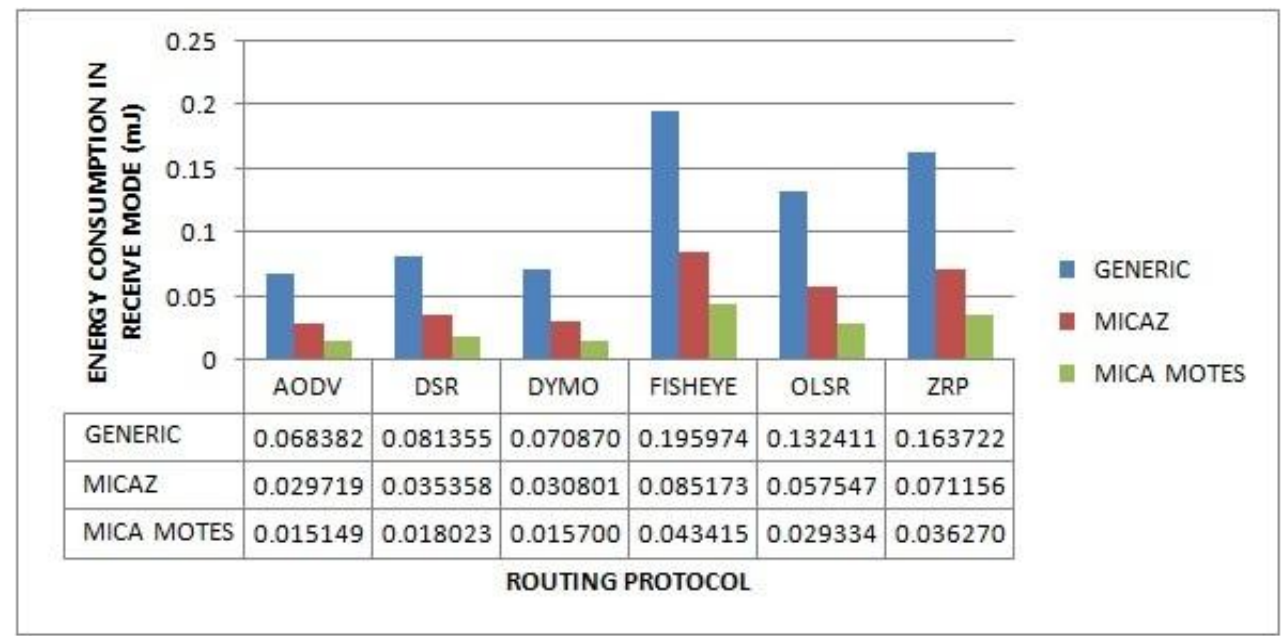

Fig. 3. Energy Consumed in Receive Mode in Physical Layer for different Ad hoc Routing Protocols

\section{3) Energy Consumed in Idle Mode :}

From the observations as shown in fig. 4, it can be deduced that the energy consumption in Idle mode behavior of ad hoc routing protocols is somewhat different from the energy consumed in Transmit and Receive mode. 
That is, first the reactive protocols (AODV, DSR and DYMO) consumes more energy in Idle mode as compared to proactive protocols (OLSR and FSR) which is reverse of energy consumed in case of Transmit and Receive mode. Second, the MicaZ energy model performs better than the other two energy models. From results it is also clear that most of the energy consumption occurs in the Idle mode for all the energy models. So the MicaZ is more energy saving model as compared to two other models while in mode.

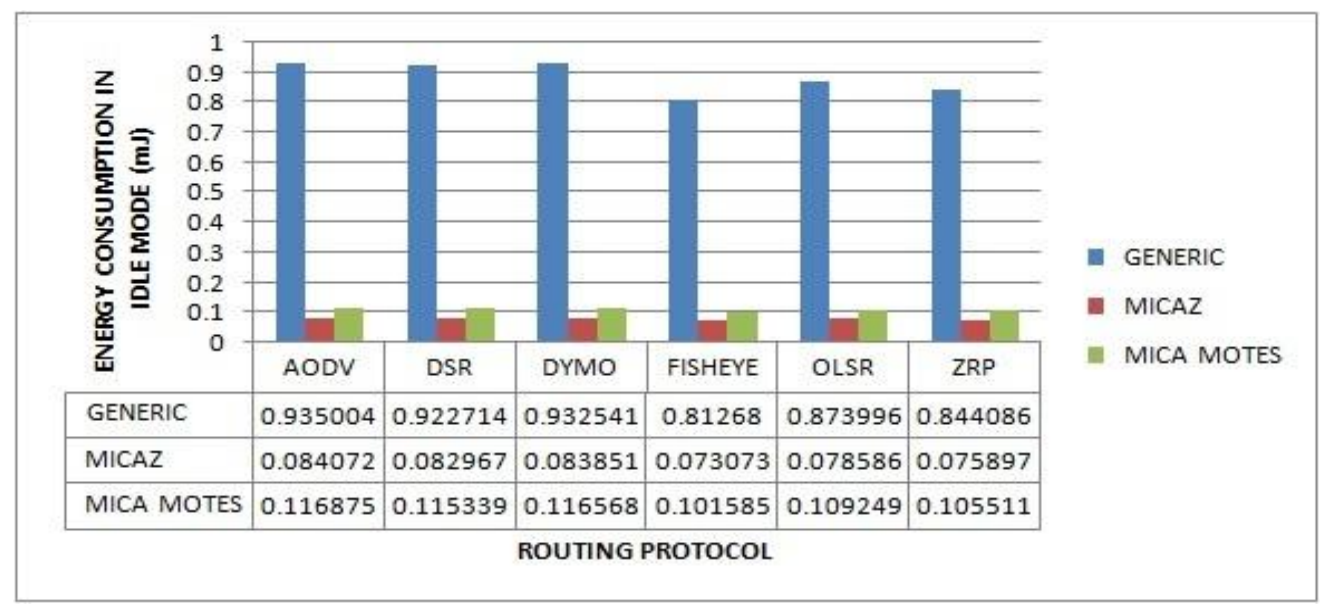

Fig. 4. Energy Consumed in Receive Mode in Physical Layer for different Ad hoc Routing Protocols

\section{4) Average End to End Delay :}

The average time taken by the packets to pass through the network is called average end to end delay. This is the time when a sender generates the packet and it is received by the application layer of destination, it is represented in seconds. It is also called Data Latency. This is the whole time that includes all possible delays caused by buffering of data packets during route discovery, queuing at the interface queue, retransmission delays at the MAC and propagation and transmission times.

As observed in fig, 5, the average end to end delay is lesser for reactive protocols (AODV and DSR) except DYMO as compared to proactive protocols (OLSR and DSR) and the hybrid protocol ZRP is having medium end to end delay. Hence it is obvious that the time at which the first packet received will be smaller for AODV and DSR as compared to OLSR and FSR.

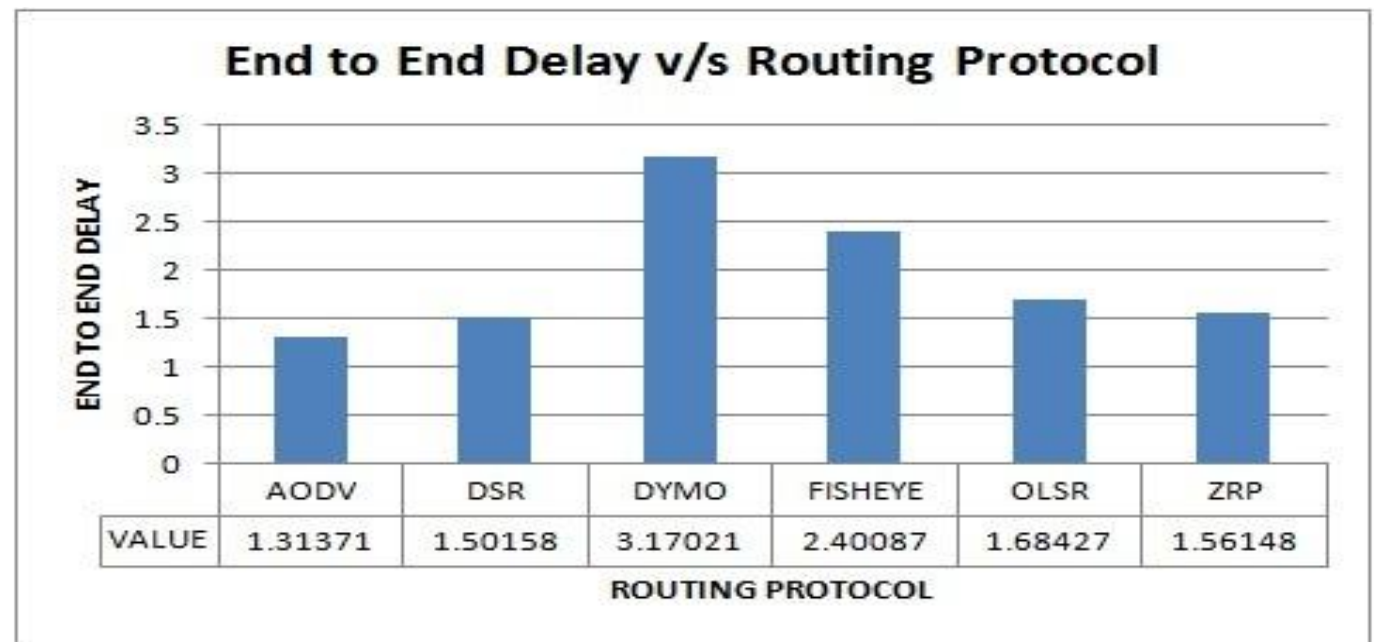

Fig. 5. Average End to End Delay in Application Layer for different Ad hoc Routing Protocols

\section{5) Average Jitter :}

The variation in the latency of packets at the destination is termed as Jitter which is caused due to congestion, topology change etc. in a network. It occurs when in a transmission scenario different packets take different amount of time in reaching from source to destination. Jitter can be measured by using the standard deviation of packet delay. Its value is required to be as low as possible for the better performance of any protocol.As shown in fig.6 the average jitter for reactive protocols (AODV, DSR, DYMO) is lower as compared to proactive protocols (OLSR and FSR) while hybrid protocol ZRP is having medium average jitter value. 


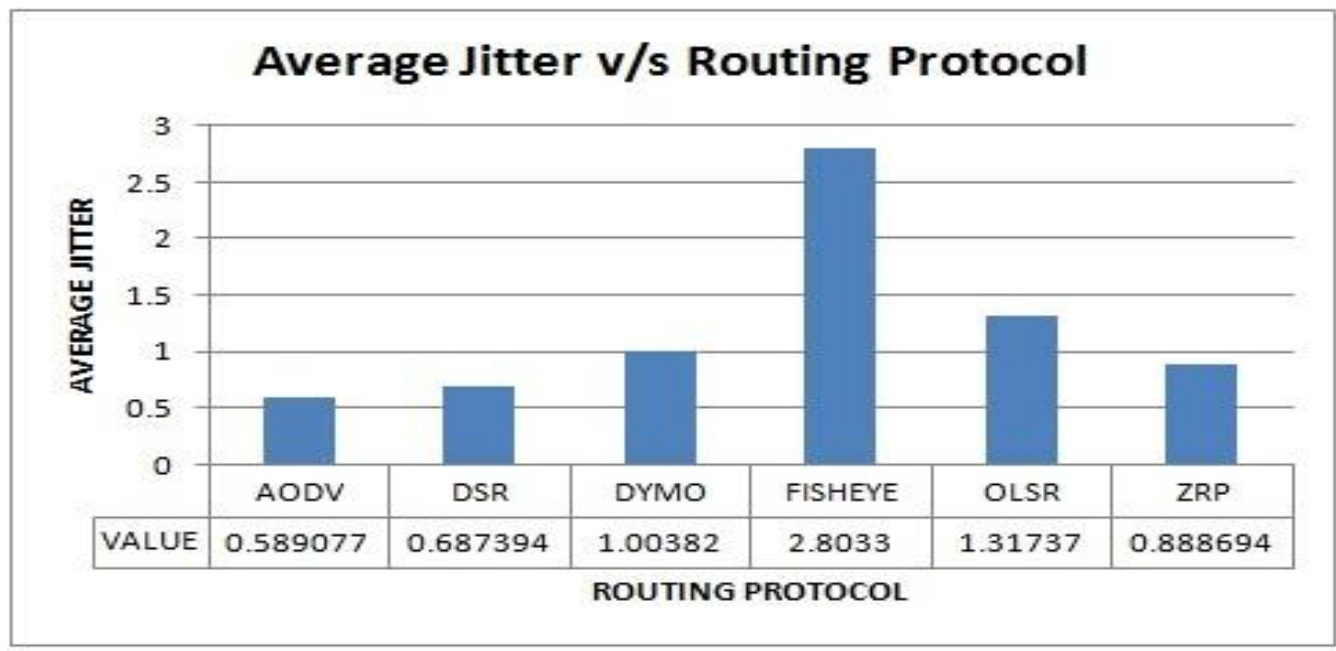

Fig. 6. Average Jitter in Application Layer for different Ad hoc Routing Protocols

\section{6) Packet Delivery Ratio :}

Packet delivery ratio is the ratio of total number of data packets received successfully at destination to number of data packets originated by the application layer of the source. PDR describes information about packet loss rate. Higher value of PDR for network indicates the better reliability of protocol.

Data packet delivery ratio of reactive protocols (AODV, DSR and DYMO) is higher as compared to proactive protocols (OLSR and FSR) as observed from fig. 7 and as usual hybrid protocol ZRP has packet delivery ratio in between proactive and reactive. Hence for the sake of reliable delivery of data packets the reactive protocol provides good results.

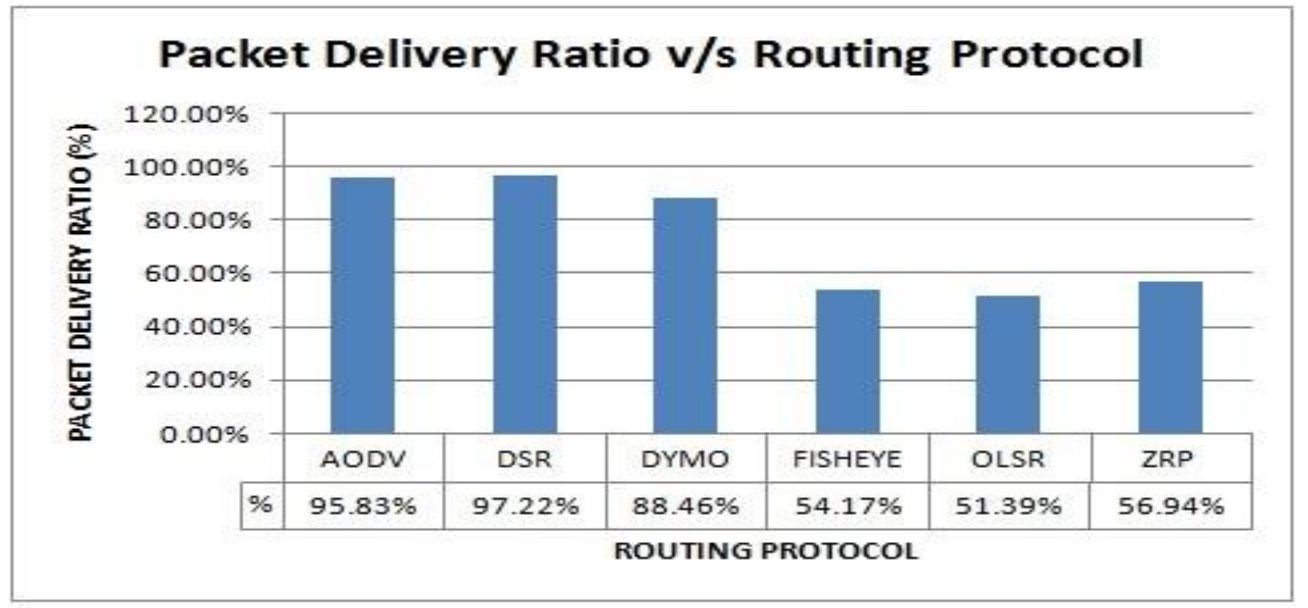

Fig. 7. Packet Delivery Ratio in Application Layer for different Ad hoc Routing Protocols

\section{7) Throughput :}

Throughput is the measure of how fast we can actually send packets through network. In other words, it is the average rate of successful data packets received at destination. It is usually measured in bits per second (bit/s or bps), and sometimes in data packets per second. In the MANET unreliable communication, limited energy, limited bandwidth and frequent topology change affect throughput.

As shown in fig.8, the throughput of DYMO is comparatively higher than AODV and DSR protocols because of its dynamic nature. Overall we can say that reactive protocols are having better throughput as compared to proactive protocols. Although ZRP is a hybrid protocol but it is having least throughput because its success depends on amount of nodes participating and reaction to traffic depends on gradient of traffic volume. Hence in terms of the number of data packets delivered at the destination node per unit time, DYMO and DSR shows a superior performance. 


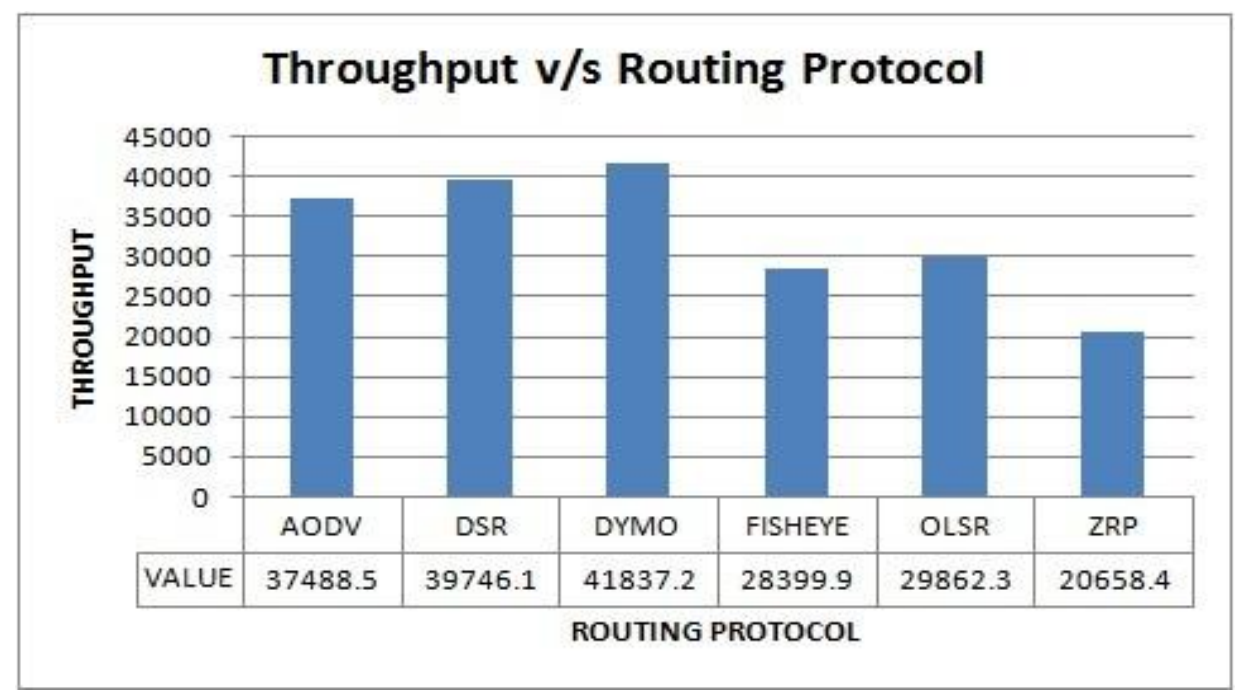

Fig. 8. Throughput in Application Layer for different Ad hoc Routing Protocols

\section{Conclusion}

Since energy consumption during communication is a major energy depletion parameter, the number of retransmissions must be reduced as much as possible to achieve extended battery life. As a result, there is a strong need for the presence of protocols which use energy efficiently and effectively as well as technology for better management of energy. Unfortunately, battery technology doesn't grow as rapidly as CPU or memory does. This study has evaluated three categories of ad hoc routing protocols for different energy models in physical layer and application layer of the networks. Overall findings suggest that the existing routing protocols have not been designed to provide energy efficient route instead to offer best efforts of less delay, more throughput and better packet delivery ratio. That is why they have shown significant differences in energy consumption. There is no single protocol qualifying all the performance metrics. From the simulation results, it has been analyzed that throughput is maximum for DYMO followed by DSR, AODV and minimum for ZRP. That is, ZRP gives the minimum throughput for all three energy models. Average jitter is least for AODV followed by DSR then DYMO and then ZRP. FSR gives the highest Average jitter value. Average End to End delay is least for AODV followed by DSR, ZRP and DYMO and FSR gives the highest average end to end delay. Maximum number of packets has been sent in DSR in all the three energy models followed by AODV, DYMO and ZRP. For energy consumption in transmit, receive mode and idle mode it has been concluded that FSR consumes maximum energy while other protocols show similar consumption with Generic as the maximum energy consuming mode. Mica motes has been proved to be the best energy saving model. From the study performed it has been analyzed that only Mica-motes consumes least amount of energy in transmit and receive mode for all the six protocols.

\section{REFERENCES}

[1] S. Mittal, P. Kaur, Performance Comparison of AODV, DSR and ZRP Routing Protocols in MANETs,, Intl. Conf. on Adv. in Comp., Control, and Telecom. Technologies, 2009, 28-29.

[2] L. M. Feeney, An Energy Consumption Model for Performance Analysis of Routing Protocols for Mobile Ad Hoc Networks, Mobile Networks and Applications, 6(3), 2001, pages 239 - 249.

[3] S. Giannoulis, C. Antonopoulos, E. Topalis, S. Koubias, ZRP versus DSR and TORA: A comprehensive survey on ZRP performance, 10th IEEE Conference Emerging Technologies and Factory Automation, Greece, 2005.

[4] Pei. G, Gerla Mand, Chen T. W, Fisheye State Routing in Mobile Ad Hoc Networks, Proceedings of the Workshops ICDCS 2000, Taipei, Taiwan, 2000, D71- D78.

[5] C. Yang, L. Tseng, Fisheye Zone Routing Protocol for Mobile Ad-Hoc Networks, Multimedia Communications Laboratory, Second IEEE Consumer Communications and Networking Conference, Taiwan, 2005.

[6] T. Clausen and P. Jacquet, Optimized Link State Routing Protocol (OLSR), IETF RFC 3626, 2003.

[7] C. E. Perkins, E. M. Belding-Royer, and S. Das, Ad Hoc On Demand Distance Vector (AODV) Routing, IETF Internet draft, 2002.

[8] Garcia J.E., Cano J.C., P. Manzon, A Novel DSR based Energy Efficient Routing Algorithm for mobile Ad hoc Networks, In: the Proc of IEEE 58th Vehicular TechnologyConference, 5(3), 2003 849-854.

[9] I. Chakeres and C. Perkins, Dynamic MANET On-demand (DYMO) Routing, Internet Draft (draft-ietf-manet-dymo-14), 2008.

[10] QualNet documentation, QualNet 6.1 Model Library:Wireless, http://www.scalablenetworks.com.

[11] Qualnet 6.1 details : www.scalable-networks.com.

[12] M.Subramanyabhat, D.Swetha and J.T. Devaraju, 2011. A Performance Study of Proactive, Reactive and Hybrid Routing Protocols using Qualnet Simulator, IJCA, 28(5), 2011. 